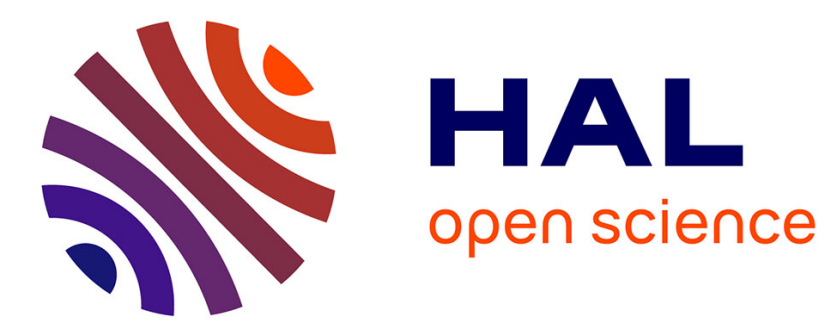

\title{
Energy Risk Management with Carbon Assets Julien Chevallier
}

\section{To cite this version:}

Julien Chevallier. Energy Risk Management with Carbon Assets. 2009. halshs-00410059

\section{HAL Id: halshs-00410059 \\ https://shs.hal.science/halshs-00410059}

Preprint submitted on 16 Aug 2009

HAL is a multi-disciplinary open access archive for the deposit and dissemination of scientific research documents, whether they are published or not. The documents may come from teaching and research institutions in France or abroad, or from public or private research centers.
L'archive ouverte pluridisciplinaire HAL, est destinée au dépôt et à la diffusion de documents scientifiques de niveau recherche, publiés ou non, émanant des établissements d'enseignement et de recherche français ou étrangers, des laboratoires publics ou privés. 


\title{
Energy Risk Management with Carbon Assets
}

\author{
Julien Chevallier*
}

February 27, 2009

* Grantham Institute for Climate Change, Imperial College London, and EconomiX-CNRS, University of Paris 10. j.chevallier@imperial.ac.uk. South Kensington Campus, SW7 2AZ London, UK. Tel : +44(0)20 7594 5796. Fax : +44(0)20 75949668. 


\begin{abstract}
This article proposes a mean-variance optimization and portfolio frontier analysis of energy risk management with carbon assets, introduced in January 2005 as part of the EU Emissions Trading Scheme. In a stylized exercise, we compute returns, standard deviations and correlations for various asset classes from April 2005 to January 2009. Our central result features an expected return of 3\% with a standard deviation $<0.06$ by introducing carbon assets - carbon futures and CERs- in a diversified portfolio composed of energy (oil, gas, coal), weather, bond, equity risky assets, and of a riskless asset (U.S. T-bills). Besides, we investigate the characteristics of each asset class with respect to the alpha, beta, and sigma in the spirit of the CAPM. These results reveal that carbon, gas, coal and bond assets share the best properties for composing an optimal portfolio. Collectively, these results illustrate the benefits of carbon assets for diversification purposes in portfolio management, as the carbon market constitutes a segmented commodity market with specific risk factors linked to the EU Commission's decisions and the power producers' fuel-switching behavior.
\end{abstract}

JEL codes: C61; G11; Q40

Keywords: Mean-variance optimization; Portfolio frontier analysis; CAPM; $\mathrm{CO}_{2}$; Carbon; Energy; Bonds; Equity; Asset Management; EU ETS; CERs 


\section{Introduction}

Carbon assets, created on January 1, 2005 as part of the European Union Emissions Trading Scheme (EU ETS) ${ }^{1}$, present very peculiar characteristics which are worth of investigation for portfolio management purposes. The determinants of $\mathrm{CO}_{2}$ prices are indeed linked to other energy markets (brent, gas, coal), and institutional events, as highlighted in previous literature (Christiansen et al. (2005), Kanen (2006), Mansanet-Bataller et al. (2007), Alberola et al. (2008)). Among these fundamentals, the fuel-switching behaviour of power operators, and the amendments to the scheme brought by the European Commission are key to understand the factors that drive the underlying price changes of carbon assets (Convery et al. (2008), Delarue et al. (2008), Ellerman and Feilhauer (2008), Chevallier et al. (2009)). Last but not least, carbon assets seem to exhibit a weak link with macroeconomic risk factors, be it with industrial production as a proxy of GDP (Alberola et al. (2009a), Alberola et al. (2009b)), or with stock and bond indices as a proxy of macroeconomic changes (Chevallier (2009)). Thus, the investigation of the interrelationships between carbon assets and energy variables on the one hand, and with stock and bond variables on the other hand, appears of particular importance for asset management.

In this article, we develop a stylized exercise to investigate the characteristics of energy, weather, bond and equity assets in terms of diversification for portfolio management. Indeed, one of the key insights of asset management to present (Bodie et al. (2008), Berk and DeMarzo (2008)) is that diversification can reduce risk substantially. The main logic behind composing a portfolio not only with bonds and equities, but also with energy commodities, is to achieve a lower level of risk. A diversified portfolio may achieve a lower level of risk, because its individual asset components do not always move together. Besides, diversification does not necessarily reduce expected return. By including relevant asset classes, the goal of portfolio management consists in raising the expected return.

The literature on portfolio management with carbon assets is still very sparse. Hasselknippe (2004) first developed commodities market perspectives with respect to managing carbon risks. Kristiansen et al. (2006) detail the key factors in carbon pricing, the fuel-mix and electricity prices that are relevant to include in carbon risk management, based on several country studies. To our best knowledge, only Mansanet-Bataller and Pardo (2008) have investigated the empirical question between $\mathrm{CO}_{2}$ prices and portfolio management. The authors investigate the properties of $\mathrm{CO}_{2}$ prices for Phase I (2005-2007) and Phase II (2008-2012) of the EU ETS, coupled with other energy (brent, natural gas), and bond variables. Their main

\footnotetext{
${ }^{1}$ The EU Emissions Trading Scheme (EU ETS) was established in 2003 by the Directive 2003/87/EC, and launched for a trial period from 2005 to 2007. Phase II now covers 2008-2012, while the functioning of the scheme has been confirmed at least until 2020 with the end of Phase III.
} 
findings consist in showing that including $\mathrm{CO}_{2}$ Phase I and Phase II prices can improve the investment opportunity set for an investor that initially invests in traditional assets.

Our results depart from previous literature (i) by providing insights into each class of asset's expected returns using the Capital Asset Pricing Model (CAPM, Merton (1973)); (ii) by applying the mean-variance optimization approach to a wider range of assets including energy, weather, bond and equity variables; and (iii) by extending the study period contained in our database from April 2005 to January 2009². To investigate the properties of the new carbon asset class in terms of portfolio management, we adopt the basic framework of the CAPM and mean-variance optimization, knowing that many developments have occurred in the field ${ }^{3}$.

More precisely, our regression analysis shows that carbon, gas, coal, and bonds assets appear particularly suitable for asset management. Our mean-variance optimization analysis shows that a global portfolio composed of energy (including carbon), weather, bond, equity risky assets and a riskless asset (U.S. T-Bills) may achieve a level of standard deviation $<0.06$ for an expected return of $3 \%$.

The composition of the globally diversified portfolio studied in this article unfolds as follows. Among carbon assets, we consider mainly futures carbon prices ${ }^{4}$. We also retain Certified Emissions Reductions (CERs) credits ${ }^{5}$. The reason behind this choice is that CERs may add diversification to a portfolio due to their fungibility with other international ETS than the EU ETS. Among energy assets, we select oil, natural gas, and coal prices. Among traditional assets, we retain bonds and equities. Finally, we choose to incorporate weather derivatives products in the composition of our portfolio, since they offer opportunities to hedge the risks attached to temperatures changes, and thus increases/decreases in $\mathrm{CO}_{2}$ emissions, and appear as a complementary asset to carbon.

The remainder of the article is organized as follows. Section 2 presents the data used. Section 3 examines asset management strategies with energy, weather, bond and equity variables. Section 5 details the optimal portfolio composition. Section 6 concludes.

\section{Data}

\footnotetext{
${ }^{2}$ Mansanet-Bataller and Pardo (2008) consider a time-period going from April 2005 to January 2008.

${ }^{3}$ More particularly, we choose not to investigate the properties of carbon assets through multifactor models such as the Intertemporal CAPM (ICAPM), and arbitrage-based models (Arbitrage Pricing Theory, APT).

${ }^{4}$ This choice is motivated by the non-reliable behaviour of carbon spot prices due to banking restrictions implemented between 2007 and 2008 (Alberola and Chevallier (2009)).

${ }^{5}$ Clean Development Mechanism (CDM) projects, introduced according to the article 12 of the Kyoto Protocol (UNFCCC (2000)), may generate Certified Emissions Reductions (CERs) credits for compliance in the EU ETS during 2008-12. The import limit is equal to 1.6 billion tonnes of offsets being allowed into the EU ETS from 2008-2020, i.e. an absolute maximum of 50\% of the effort will be achievable through the CDM, coupled with quality criteria.
} 
This section discusses the source of each time-series chosen for energy, weather, bond and equity variables, as well as the robustness checks implemented.

\subsection{Source and descriptive statistics}

The source of the data is Thomson Financial Datastream and Reuters, unless otherwise indicated. The various asset classes that we examine in this article are detailed in Tables 1 to 3 (see the Appendix) which provide the expected returns and standard deviations (Table 1); the correlation matrix (Table 2); and descriptive statistics (Table 3) for the energy, weather, bond and equity assets. The expected return and standard deviation for each asset class are used in Section 4 for the composition of the optimal portfolio. When each asset class is examined as part of a portfolio, we measure asset risk by the covariance between asset return and the return on the market portfolio.

\section{Insert Figure 1 about here}

The returns for energy and weather assets are displayed in Figure 1.

\section{Insert Figure 2 about here}

The returns for bond and equity assets are presented in Figure 2.

According to the matrix of cross-correlations between sector variables reported in Table 2 , no simple correlation is over around $60 \%$ in absolute value. Since it is possible to have low correlations together with colinearity, we have investigated the presence of multicolinearity by comptuting the inflation of variance between explanatory variables. These calculations did not reveal serious problematic multicolinearities ${ }^{6}$.

For carbon assets, it is worth emphasizing in Table 3 that the kurtosis coefficient is by far higher than 3 , which is the value of the kurtosis coefficient for the normal distribution. This excess kurtosis denotes a high likelihood of outliers. Second, the skewness coefficient is different from zero and negative, which highlights the presence of asymmetry.

Let us detail in the next section the time-series used for each asset class considered in this article.

\subsection{Energy, weather, bond and equity assets}

\footnotetext{
${ }^{6}$ To conserve space, these results are not reproduced in the article and may be obtained upon request to the authors.
} 
For carbon assets, we choose the carbon futures contract of maturity December $2008^{7}$ traded on the European Climate Exchange (ECX) from April 22, 2005 to December 15, 2008, i.e. from the opening of the ECX market to the expiration date of the 2008 carbon futures contract. The carbon prices recorded in our database are daily closing prices in $€$. One European Union Allowance (EUA) is equal to one tonne of $\mathrm{CO}_{2}$ emitted in the atmosphere. For diversification purposes, we also consider the price of secondary CERs credits, recorded as daily closing prices by the Reuters CER Price Index from February 2, 2008 to January 21, 2009. One secondary CER is equal to one EUA, and thus to the same $\mathrm{CO}_{2}$-equivalent.

For natural gas assets, we use the Zeebrugge Natural Gas Next Month price. For the electricity price, we use the Electricity Powernext Baseload price. For coal prices, we use the Coal Rotterdam futures. For oil products, we use the NYMEX Crude Oil Futures. Gas and electricity prices are traded in €/MWh. Coal prices are traded in €/ton. Oil prices are traded in $\$ /$ barrel ${ }^{8}$. All energy prices recorded in our database are daily closing prices from January 1 , 2005 to January 15, 2009.

For weather derivatives products, we consider the Climate Futures Eco Clean Energy Index traded on the Intercontinental Exchange (ICE). The database contains daily closing prices from July 13, 2007 to January 21, $2009^{9}$.

For bonds, we retain the ECB 5-year Euro Benchmark Bond. For equities, we consider the Euronext 100 Price Index. Both bond and equity variables have been chosen for their ability to track changes in global market trends. For both of these variables, we use daily closing prices from December 31, 2004 to January 21, 2009.

As is standard in the financial literature (Bodie et al. (2008), Berk and DeMarzo (2008)), we have considered for the riskless asset daily closing prices on the one-month U.S. Treasury Bill (T-Bill) ${ }^{10}$ from April 1, 2005 to January 21, 2009.

In the next section, we discuss several robustness checks implemented.

\subsection{Sensitivity tests}

The purpose of this section is to demonstrate that the results obtained in Sections 3 and 4 are not sensitive to the choice of the time-series for energy, weather, bond and equity assets.

As sensitivity tests, we have considered the ECX December 2009 contract for carbon prices, the ECX CER Futures for CERs prices, the European Energy Exchange (EEX) off-peak

\footnotetext{
${ }^{7}$ This choice of a carbon futures contract for delivery during Phase II of the EU ETS is motivated by the erratic behaviour of carbon prices during Phase I due to the banking restrictions implemented between Phase I and Phase II (Alberola and Chevallier (2009)).

${ }^{8}$ To ensure that all energy prices are traded with the same currency, we converted dollars to euros using the European Central Bank daily exchange rate (available at http://www.ecb.int ).

${ }^{9}$ As for oil products, the prices of such weather derivatives contracts have been converted to euro using the $€ / \$$ exchange rate by the ECB.

${ }^{10}$ Data for the T-Bill rate may be obtained at http://research.stlouisfed.org/fred2/
} 
electricity price, the London brent crude oil price, the natural gas-Henry Hub price, the daily coal futures Month Ahead price CIF ARA, the ICE Weather Futures contract, the Bond Schatz and Bond Bulb treasury bills, the Dow Jones EuroSTOXX 50 Price Index, and the Standard \& Poor's Euro Price Index. By implementing these alternative robustness tests, the results commented below were not materially affected ${ }^{11}$.

We discuss in the next section how to implement asset management strategies with the energy, weather, bond and equity assets contained in our database.

\section{Asset management with energy, weather, bond and equity variables}

This section reviews how to choose a portfolio composed of energy commodities, weather derivatives, bonds, and equities. We detail how expected returns are determined, and how they are related to energy risk management.

\subsection{Expected excess return and market risk premium}

Let $N$ be the total number of risky assets. The excess return of asset $n$ may be defined as:

$$
R_{n}-R_{f}(1)
$$

with $R_{n}$ the return on the risky asset, and $R_{f}$ the return on the riskless asset.

Then, let us define the expected excess return of asset $n$ as:

$$
E\left(R_{n}\right)-R_{f}
$$

where $E($.$) denotes the expected value of the asset's return.$

Next, we define the market portfolio as the value-weighted portfolio of the $N$ risky assets:

$$
\sum_{n=1}^{N} P_{n} s_{n}
$$

with $P_{n}$ the price of one asset share, and $s_{n}$ the total number of shares.

Similarly, the weight of asset $n$ in the market portfolio is:

$$
\frac{P_{n} s_{n}}{\sum_{n=1}^{N} P_{n} s_{n}}
$$

Now, let $R_{M}$ be the return on the market portfolio. The market risk premium may be computed as:

\footnotetext{
${ }^{11}$ To conserve space, sensitivity tests are not reproduced in the article, and may be obtained upon request to the authors.
} 


$$
E\left(R_{M}\right)-R_{f}
$$

i.e. as the expected excess return of the market portfolio.

Following these basic definitions, we recall in the next section how to measure various types of risks involved in portfolio management.

\subsection{Systematic and idiosyncratic risks}

Based on the CAPM ${ }^{12}$ (Merton (1973)), when studying asset returns we may estimate the following regression equation:

$$
R_{n}-R_{f}=\alpha_{n}+\beta_{n}\left(R_{M}-R_{f}\right)+\varepsilon_{n}
$$

where the variation of asset $n$ may be decomposed into:

- the systematic risk $\beta_{n}\left(R_{M}-R_{f}\right)$, i.e. the risk perfectly correlated with the market portfolio. This type of risk affects all assets, such as macroeconomic shocks affecting the economy.

- the idiosyncratic risk $\varepsilon_{n}$, i.e. the risk uncorrelated with the market portfolio. This type of risk affects only one asset. For equities for instance, idiosyncratic risk corresponds to events affecting only a particular company or industry.

From there, we may derive three characteristics of an asset:

1. the beta measures the asset's sensitivity to market movements ${ }^{13}$ :

$$
\beta_{n}=\frac{\operatorname{Cov}\left(R_{n}, R_{M}\right)}{V\left(R_{M}\right)}(7)
$$

2. the alpha measures the asset's attractiveness;

3. the sigma is the standard deviation of $\varepsilon_{n}$, i.e. the idiosyncratic risk.

In the next section, we provide an estimate of betas, alphas and sigmas for all types of risky assets considered as part of our globally diversified portfolio.

\subsection{Regression analysis}

Taking expectations of eq.(6),

$$
E\left(R_{n}\right)-R_{f}=\alpha_{n}+\beta_{n}\left(E\left(R_{M}\right)-R_{f}\right)
$$

we may get some insights on the alpha, beta and market risk premium of each asset class contained in our database.

To take into account the heteroskedasticity present in the excess returns of financial and energy assets alike, we implement the following ARCH(1,1) model (Engle (1982)):

\footnotetext{
${ }^{12}$ The assumptions underlying the CAPM may be summarized as follows: there are $N$ risky asset and a riskless asset, short sales are costless, investors care only about mean and variance, investors have the same beliefs, and investors have an one-period planning horizon.

${ }^{13}$ Holding all else equal, if the return on the market portfolio is higher by $1 \%$, then the return on asset $n$ is higher by $\beta_{n}$.
} 


$$
\begin{aligned}
& E\left(R_{n}\right)-R_{f}=\alpha_{0}+\alpha_{1}\left(E\left(R_{n}\right)-R_{f}\right)_{t-1}+\beta_{n}\left(E\left(R_{M}\right)-R_{f}\right)+\varepsilon_{t} \\
& \sigma_{t}^{2}=\omega+\varphi \varepsilon_{t-1}^{2}
\end{aligned}
$$

with a Gaussian innovation distribution, as is standard in the financial economics literature (Hamilton (1994)). $R_{t}$ is the return on the asset price, $R_{t-1}$ is a proxy for the mean of $R_{t}$ conditional on past information, and $\varepsilon_{t}$ is the error term. Eq. (9) is estimated by Quasi Maximum Likelihood (QML, Gourieroux et al. (1984)). The estimate covariance matrix is estimated using the BHHH matrix (Berndt et al. (1974)).

\subsection{Estimation results}

Eq.(8) is estimated for each asset class composing our portfolio of energy, weather, bond and equity variables using the ARCH modelling structure detailed in eq.(9). Estimation results may be found in Tables 4 to 11 (see the Appendix).

We comment below Tables 4 to 11 with respect to the values of the alpha, beta, and sigma coefficients. However, it should be kept in mind that an asset's expected return depends on the asset's risk through the asset's beta (i.e. the systematic risk), and not through the asset's sigma (i.e. the idiosyncratic risk). The basic insight of the CAPM is indeed that the systematic risk - and not the idiosyncratic risk - is priced by the market. In other words, the relevant measure of risk is beta, and not the variance.

In Table 4 (see the Appendix), we notice that the alpha coefficient for carbon excess returns is statistically significant at the $1 \%$ level. This result highlights the carbon asset's attractiveness for the composition of the optimal portfolio. On the contrary, the carbon asset's sensitivity to market movements beta is not statistically significant. The sigma coefficient is equal to 0.61 . This value reveals a medium level of idiosyncratic risk for carbon assets.

In Table 5 (see the Appendix), we observe that the alpha coefficient for natural gas assets is not statistically significant. The beta coefficient however is significant at the $1 \%$ level and negative. This result indicates that the excess returns on natural gas prices are negatively and statistically significantly correlated with market movements. This characteristic of natural gas products appears of particular importance for diversification purposes in portfolio management. The sigma coefficient is equal to 2.77, which corresponds to a high level of idiosyncratic risk.

In Table 6 (see the Appendix), none of the alpha or beta coefficients are statistically significant for the excess returns on the electricity variable. Besides, the level for the idiosyncratic risk coefficient sigma is very high (8.97). These results suggest that due to the well-known high level of peaks in the time-series of electricity prices (Joskow (2007)), this 
variable does not appear particularly suitable for asset management strategies compared to the raw prices of other energy sources, such as oil, gas and coal ${ }^{14}$.

In Table 7 (see the Appendix), we note that the alpha coefficient for coal excess returns is statistically significant at the $1 \%$ level, which underlines this asset's attractiveness for portfolio management. Besides, the beta coefficient is also significant at the $10 \%$ level and negative. As for the natural gas variable, this result shows that coal asset's sensitivity is negatively correlated with market movements, which is of interest for diversification purposes. The sigma coefficient is equal to 0.87 , which reveals a medium level of idiosyncratic risk.

In Table 8 (see the Appendix), none of the alpha or beta coefficients for oil excess returns are statistically significant. The level of idiosyncratic risk for oil assets is in the medium range, with a value of 1.46. Due to these characteristics, oil assets do not surprisingly appear as very suitable for portfolio management either ${ }^{15}$.

In Table 9 (see the Appendix), we note that neither the alpha nor the beta coefficients are statistically significant for weather excess returns. Besides, the level of idiosyncratic risk is very high, with a value of sigma equal to 5.20 . Thus, we may conclude based on these results that derivatives products do not appear to share the required properties for diversification and increasing returns purposes in portfolio management ${ }^{16}$.

In Table 10 (see the Appendix), we observe that the alpha coefficient for bonds is not statistically significant. This result is not surprising, since bonds are primarily purchased for the security of investments, and thus not for their attractiveness in terms of returns. The beta coefficient is statistically significant at the $1 \%$ level and positive. In line with the central role played by national governments in monetary policy, this result illustrates the strong link between the bond market and movements in global equity and commodity markets. The sigma coefficient is low (0.07), which confirms bond asset's interest for pooling risks.

In Table 11 (see the Appendix), none of the alpha or beta coefficients appear statistically significant for the excess return of CERs. This result does not appear especially surprising, given the high level of risks attached to the delivery of CDM credits to project developers (IETA (2008)). Like carbon assets, CERs carry a medium level of idiosyncratic risk, with a value of the sigma coefficient equal to 0.41 .

\footnotetext{
${ }^{14}$ Nevertheless, we choose to keep this variable in the determination of our optimal portfolio in the next section, due to the central role played by power producers on the European emissions market, which greatly influence the determination of the carbon price (Delarue et al. (2008), Ellerman and Feilhauer (2008)).

${ }^{15}$ However, due to the clear link between petroleum consumption and GDP (Lutz (2008)) on the one hand, and to the fact that oil products are the most traded assets among energy commodities (Kang et al. (2009)), we choose to keep oil assets in the composition of our portfolio in the next section.

${ }^{16}$ As for electricity and oil, weather appears as an important determinant of the price of carbon assets (Kanen (2006), Alberola et al. (2008)). Thus, we choose to keep this variable in the composition of our globally diversified portfolio in the next section.
} 
Among all the energy, bond and equity assets, this regression analysis indicates that the carbon, gas, coal, and bond assets share the best properties in terms of (i) sensitivity to market movements, (ii) attractiveness, or (iii) level of idiosyncratic risk to enter the optimal composition of our portfolio ${ }^{17}$.

To analyse the interplay between energy, weather, bond and equity assets - which is the purpose of the stylized exercise developed in this article - we decide to include all of them in the composition of our portfolio in the next section.

\section{Mean-variance optimization and the portfolio frontier}

Following the review of the properties of energy, weather, bonds, and equities assets in Section 3, we detail in this section the optimal composition of the portfolio based on meanvariance optimization and portfolio frontier analysis.

\subsection{Portfolio frontier with risky assets only}

In this section, we explore how to choose the optimal portfolio composed of energy, weather, bond and equity assets. This question can be addressed in two steps:

1. Among all portfolios with a given expected return, which is the portfolio with the minimum variance? This first step will give us a set of portfolio, one for each expected return. This set is called the portfolio frontier (PF), whose elements are frontier portfolios.

2. Which is the best portfolio on the PF? This answer will depend on how we trade off risk and return, and on the level of risk aversion of a specific group of investors.

Using the historical data from April 2005 to January 2009 for energy, weather, bonds and equities variables as explained in Section 2, we consider below the optimization program of choosing the global portfolio. The statistical properties of returns for all classes of assets, including expected returns, sample means, standard deviations, and correlations may be found in Tables 1 to 3 (see the Appendix) ${ }^{18}$.

Among all portfolios that have a given expected return $(E)$, the optimization problem consists in choosing the portfolio with the minimum variance:

\footnotetext{
17 As the CAPM implies than an asset's expected return depends on risk only through beta, this conclusion shall be read especially in the light obtained for the beta coefficient of each asset class.

${ }^{18}$ We should always keep in mind that mean-variance optimization is only as precise as these estimates are. While the estimates for standard deviations and correlations are generally quite precise, the estimates for expected returns are quite imprecise (i.e. historical data for bonds and equities over a 75-year sample report a standard error around 2.5\% (Bodie et al. (2008), Berk and DeMarzo (2008).)
} 


$$
\begin{aligned}
& V(R)=\sum_{n=1}^{N} w_{n}^{2} V\left(R_{n}\right)+2 \sum_{n<m} w_{n} w_{m} \operatorname{Cov}\left(R_{n}, R_{m}\right) \\
& \sum_{n=1}^{N} w_{n}=1 \\
& E(R)=\sum_{n=1}^{N} w_{n} E\left(R_{n}\right)=E
\end{aligned}
$$

with $w_{n}, n=\{1, \ldots, N\}$ the portfolio weights to minimize.

The portfolio frontier analysis with risky assets only is displayed in Figure $3^{19}$.

\section{Insert Figure 3 about here}

Assuming that we only care about mean and variance, we only need to consider portfolios on the PF. By comparing portfolios on the PF in Figure 3, we may observe that the optimal portfolio achieves a standard deviation $<0.1$ for an expected return around 3\%. This result illustrates the benefits of diversification to reduce idiosyncratic risk by adding energy and weather variables to usual bonds and equities variables, and more particularly by managing energy risk with a new class of carbon assets. This exercise thus demonstrates that diversification outside a group of assets is more effective in reducing risk ${ }^{20}$.

We develop in the next section a slight variation of the mean-variance optimization program by including also a riskless asset.

\subsection{Portfolio frontier with a riskless asset}

In this section, all frontiers portfolios are combinations of the riskless asset and the tangent portfolio (TP). We use the U.S. T-bills as the riskless asset. We only need to choose the weights of the risky assets, $w_{n}, n=\{1, \ldots, N\}$, given that the weight of the riskless asset is:

$$
1-\sum_{n=1}^{N} w_{n}
$$

The variance of the riskless asset is indeed equal to zero, as is its covariance with all risky assets. The optimization problem in eq.(10) needs to be rewritten as follows:

$$
\begin{aligned}
& V(R)=\sum_{n=1}^{N} w_{n}^{2} V\left(R_{n}\right)+2 \sum_{n<m} w_{n} w_{m} \operatorname{Cov}\left(R_{n}, R_{m}\right) \\
& E(R)=\sum_{n=1}^{N} w_{n} E\left(R_{n}\right)+\left(1-\sum_{n=1}^{N} w_{n}\right) R_{f}=E
\end{aligned}
$$

\footnotetext{
${ }^{19}$ Note that allowing short sales - selling an asset that we do not own - will only result in expanding the $\mathrm{PF}$, as is standard in the portfolio management literature (Bodie et al. (2008), Berk and DeMarzo (2008)).

${ }^{20}$ Note this comment applies as long as diversification within a group of assets allows reducing, and eventually eliminating, idiosyncratic risk. However, it cannot eliminate systematic risk.
} 
The $\mathrm{PF}$ is delimited by the line linking the riskless asset with the $\mathrm{TP}^{21}$. Thus, to determine the PF, we only need to solve the optimization problem, and to draw the line linking that portfolio to the riskless asset.

The portfolio frontier analysis with a riskless asset is presented in Figure 4.

\section{Insert Figure 4 about here}

By considering the line linking the riskless asset with the points on the hyperbola ${ }^{22}$, we notice in Figure 4 that the optimal portfolio in this configuration allows achieving a standard deviation $<0.06$ for an expected return around 3\%. Thus, departing from the benchmark case in Section 4.2, the inclusion of a riskless asset such as the T-Bill rate allows minimizing the variance for the same level of expected return.

We are now able to answer carefully to the question "which portfolio to choose?". Assuming that we care only about mean and variance, we should choose indeed a portfolio on the PF. Which portfolio depends then on how we trade off risk and return, i.e. on the level of risk aversion ${ }^{23}$. If we are very risk-averse, we should choose a portfolio closer to the riskless asset. If we are not very risk-averse, we should choose a portfolio closer to the TP, and even above the TP. For investors as a group, the demand will be a combination of tangent portfolio and riskless asset.

These comments conclude our stylized exercise of portfolio management including bonds, equities, energy and weather variables, as well as a new class of carbon assets.

\section{Concluding Remarks}

This article provides a stylized exercise to investigate the diversification benefits that may be drawn from using carbon assets in portfolio management. Apart from traditional assets, there is a need on the carbon market to take into account the interrelationships with other energy markets, weather influences, and macroeconomic conditions, as shown in previous literature (Christiansen et al. (2005), Alberola et al. (2008), Chevallier (2009)). Thus, we introduce two types of carbon assets - carbon futures and CERs - among a global portfolio composed of energy commodities (oil, coal, gas), weather derivatives, bonds and equities. Our study period goes from April 2005 to January 2009.

\footnotetext{
${ }^{21}$ The basic insight here is that at the market equilibrium demand equals supply, and in particular the TP coincides with the market portfolio.

${ }^{22}$ In this context, the portfolio frontier is indeed represented by the line with the steepest slope.

${ }^{23}$ Chevallier et al. (2009) demonstrate that the level of risk aversion is higher on the carbon market than on equity markets. This result is due to the high level of institutional uncertainty on this emerging commodity market. The authors however point out that the values for risk aversion on the carbon market should progressively converge to the values found on equity markets, as the formation of anticipations becomes more homogeneous among market operators.
} 
Based on a CAPM framework, we show (i) that carbon, gas, coal and bonds share the required properties in terms of betas to compose a globally diversified portfolio, and (ii) that a global portfolio with energy (including carbon), weather, bond, equity risky assets and a riskless assets (U.S. T-Bills) achieves a level of standard deviation $<0.06$ for an expected return of $3 \%$.

Collectively, these results provide insights into the benefits of introducing carbon assets for diversification purposes in portfolio management. Unlike other energy markets which exhibit a direct link with macroeconomic conditions, risk factors on the carbon market are mainly linked to power producers' fuel-switching behaviour and institutional decision changes by the EU Commission.

Finally, portfolio management with carbon assets is yet another attempt at eliminating idiosyncratic risk among a range of diversified investments, but not systematic risk, as the recent "credit crunch" crisis has shown the dependency of all types of assets to macroeconomic shocks. 


\section{References}

Alberola, E., and Chevallier, J., 2009. "European carbon prices and banking restrictions: Evidence from Phase I (2005-2007)”. The Energy Journal 30(3), 107-136.

Alberola, E., Chevallier, J., and Chèze, B., 2008. "Price drivers and structural breaks in European carbon prices 2005-2007”. Energy Policy 36(2), 787-797.

Alberola, E., Chevallier, J., and Chèze, B., 2009a. "The EU Emissions Trading Scheme: Disentangling the Effects of Industrial Production and $\mathrm{CO}_{2}$ Emissions on European Carbon Prices”. International Economics 116, forthcoming.

Alberola, E., Chevallier, J., and Chèze, B., 2009b. "Emissions Compliances and Carbon Prices under the EU Trading Scheme”. Journal of Policy Modeling, forthcoming.

Berk, J., and DeMarzo, P. 2008. Corporate Finance, Pearson International Edition.

Berndt, E.K., Robert, E.,Hall, B.H., and Hausman, J.A., 1974. "Estimation and Inference in Nonlinear Structural Models”. Annals of Economic and Social Measurement 3, 653-665.

Bodie, Z., Kane, A., and Marcus, A.J. 2008. Investments, $7^{\text {th }}$ Edition, McGraw Hill.

Chevallier, J. 2009. "Carbon futures and macroeconomic risk factors: A view from the EU ETS”, Energy Economics, forthcoming.

Chevallier, J., Ielpo, F., and Mercier, L., 2009. "Risk aversion and institutional information disclosure on the European carbon market: a case-study of the 2006 compliance event”. Energy Policy 37(1), 15-28.

Christiansen, A., Arvanitakis, A., Tangen, K., and Hasselknippe, H., 2005. 'Price determinants in the EU emissions trading scheme'. Climate Policy 5, 15-30.

Convery, F.J., Ellerman, A.D., and de Perthuis, C. 2008. 'The European Carbon Market in Action: Lessons from the First Trading Period'. Interim Report. MIT-CEEPR, Mission Climat Caisse des Dépôts and University College Dublin.

Ellerman, A.D.,and Feilhauer, S. 2008. “A Top-down and Bottom-up look at Emissions Abatement in Germany in response to the EU ETS”, MIT-CEEPR, Working Paper 08-017.

Engle, R. F. 1982. "Autoregressive Conditional Heteroscedast-icity with Estimates of the Variance of U.K. Inflation”. Econometrica 50, 987-1008.

Gourieroux, C., Monfort, A., and Trognon, A. 1984. "Pseudo maximum likelihood methods: Theory”, Econometrica 52(3), 681-700.

Hamilton, J.D. 1994. Time Series Analysis, Princeton University Press.

Hasselknippe, H. 2004. "Managing carbon risks: A commodities market perspective”, Climate Change and Business, Communication, Auckland.

IETA (2008), "State of the CDM 2008: Facilitating a Smooth Transition into a Mature Environmental Financing Mechanism”, International Emissions Trading Association, Report.

Joskow, P. 2007 "Competitive Electricity Markets and Investment in New Generating Capacity,” in The New Energy Paradigm, edited by Dieter Helm, Oxford University Press. 
Kang, S.H., Kang, S.M., and Yoon, S.M. 2009. "Forecasting volatility of crude oil markets", Energy Economics 31, 119-125.

Kanen, J.L.M. 2006. Carbon Trading and Pricing. Environmental Finance Publications.

Kristiansen, T., Wolbers, R., Eikmans, T., and Reffel, F. 2006. “Carbon Risk Management”, $9^{\text {th }}$ International Conference on Probabilistic Methods Applied to Power Systems, Proceedings, KTH Stockholm, Sweden.

Lutz, K. 2008, “The Economic Effects of Energy Price Shocks”, Journal of Economic Literature 46(4), 871-909.

Mansanet-Bataller, M., Pardo, A., and Valor, E., 2007. ' $\mathrm{CO}_{2}$ Prices, Energy and Weather'. The Energy Journal 28 (3), 67-86.

Mansanet-Bataller, M., and Pardo, A. 2008. ' $\mathrm{CO}_{2}$ Prices and Portfolio Management'. SSRN Working Paper \#1156975.

Merton, R.C. 1973. “An Intertemporal Capital Asset Pricing Model”, Econometrica, 41(5), 867887.

UNFCCC. 2000. "Procedures and Mechanisms Relating to Compliance under the Kyoto Protocol: Note by the co-Chairmen of the Joint Working Group on Compliance”, United Nations Framework Convention for Climate Change, Bonn. Report. 
Appendix 


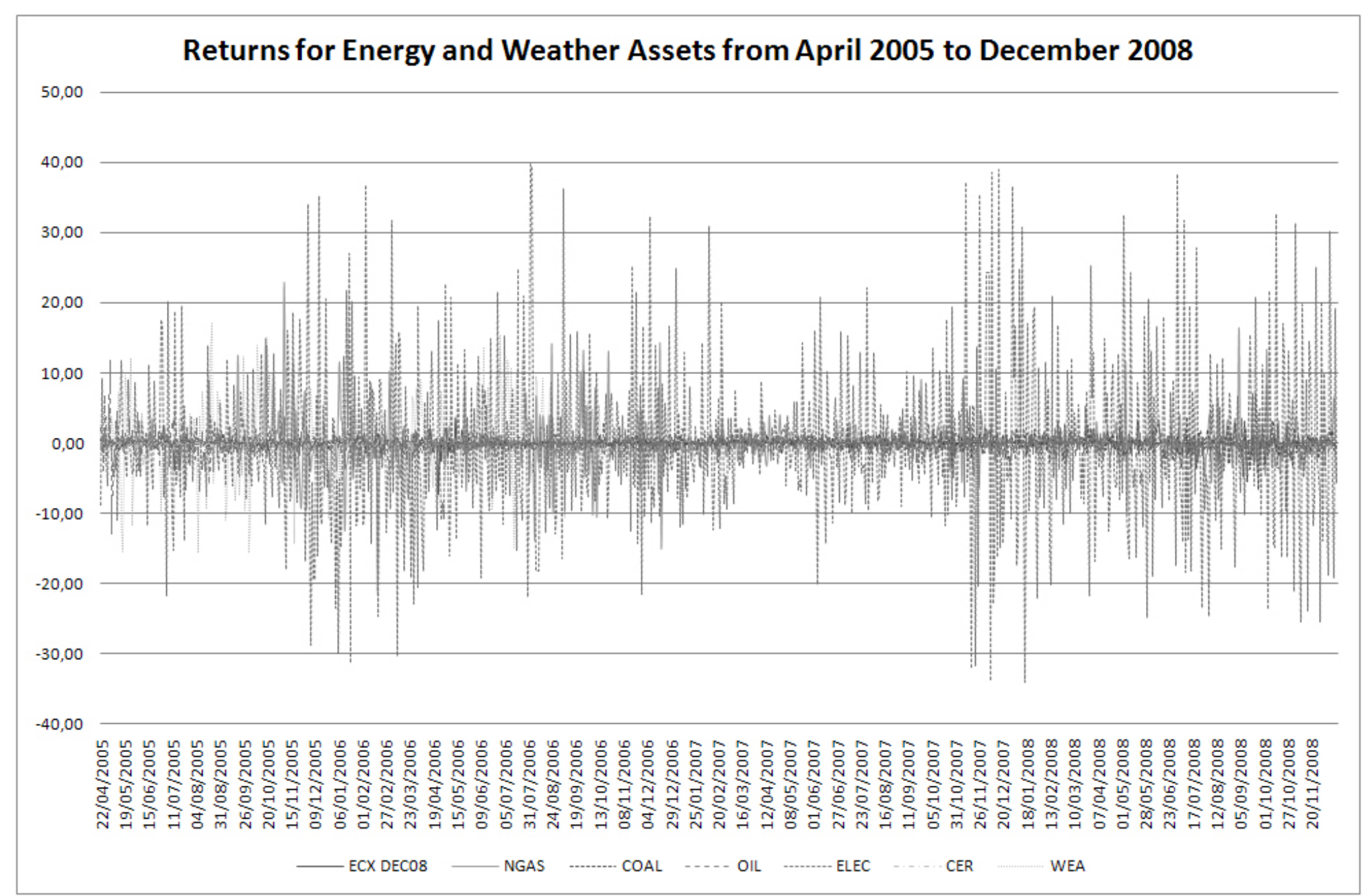

Figure 1: Returns for Energy and Weather Assets

Source: Thomson Financial Datastream and Reuters

Note: ECX DEC08 refers to the ECX carbon futures contract of maturity December 2008, Gas to the natural gas variable, Elec to the electricity variable, Coal to the coal variable, Oil to the crude oil variable, WEA to the weather derivatives contract, CER to Certified Emissions Reduction credits as defined above. 


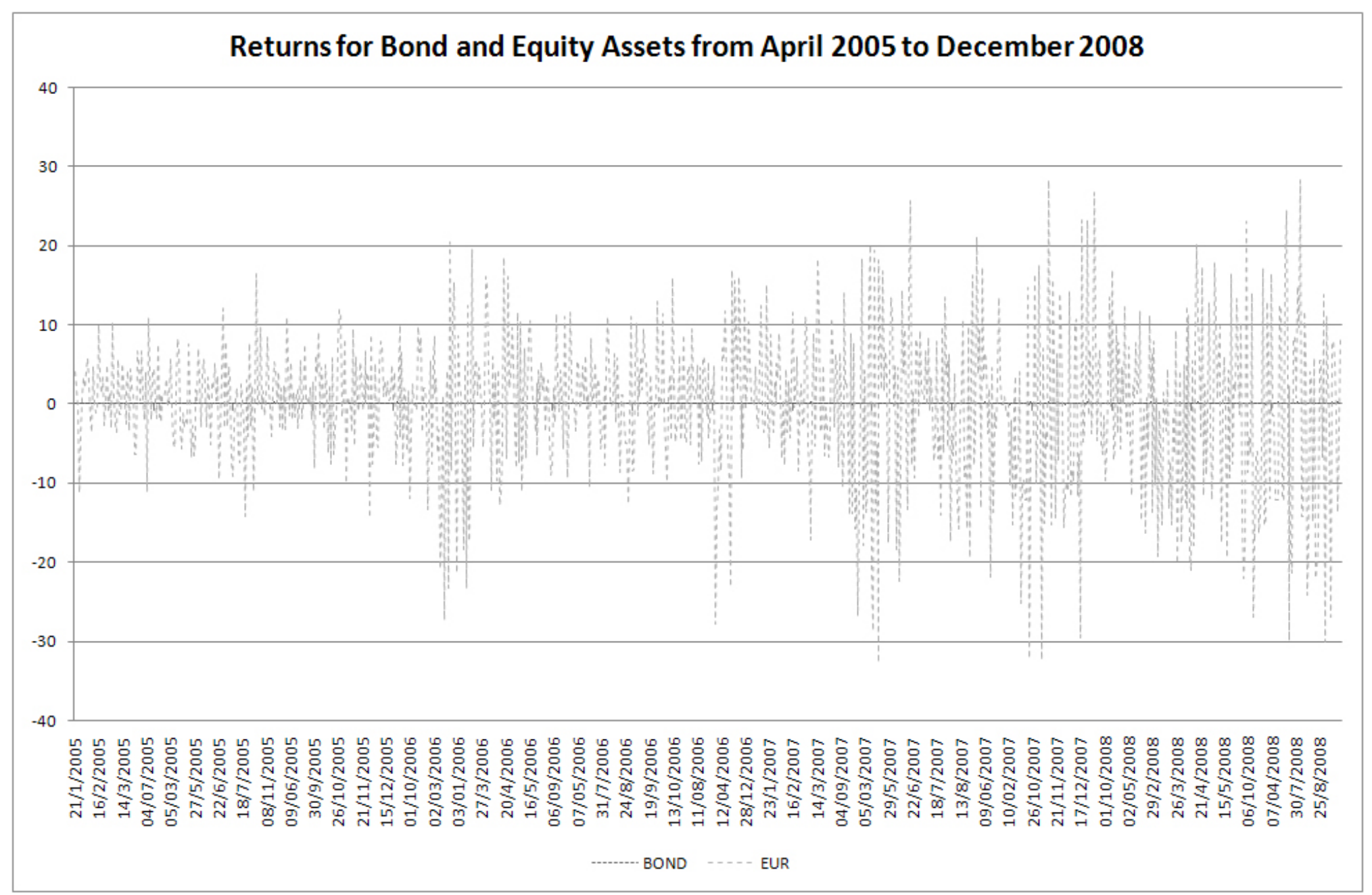

Figure 2: Returns for Bond and Equity Assets

Source: Thomson Financial Datastream and Reuters

Note: BOND refers to the bond variable, and EUR to the Euronext 100 price index as defined above. 


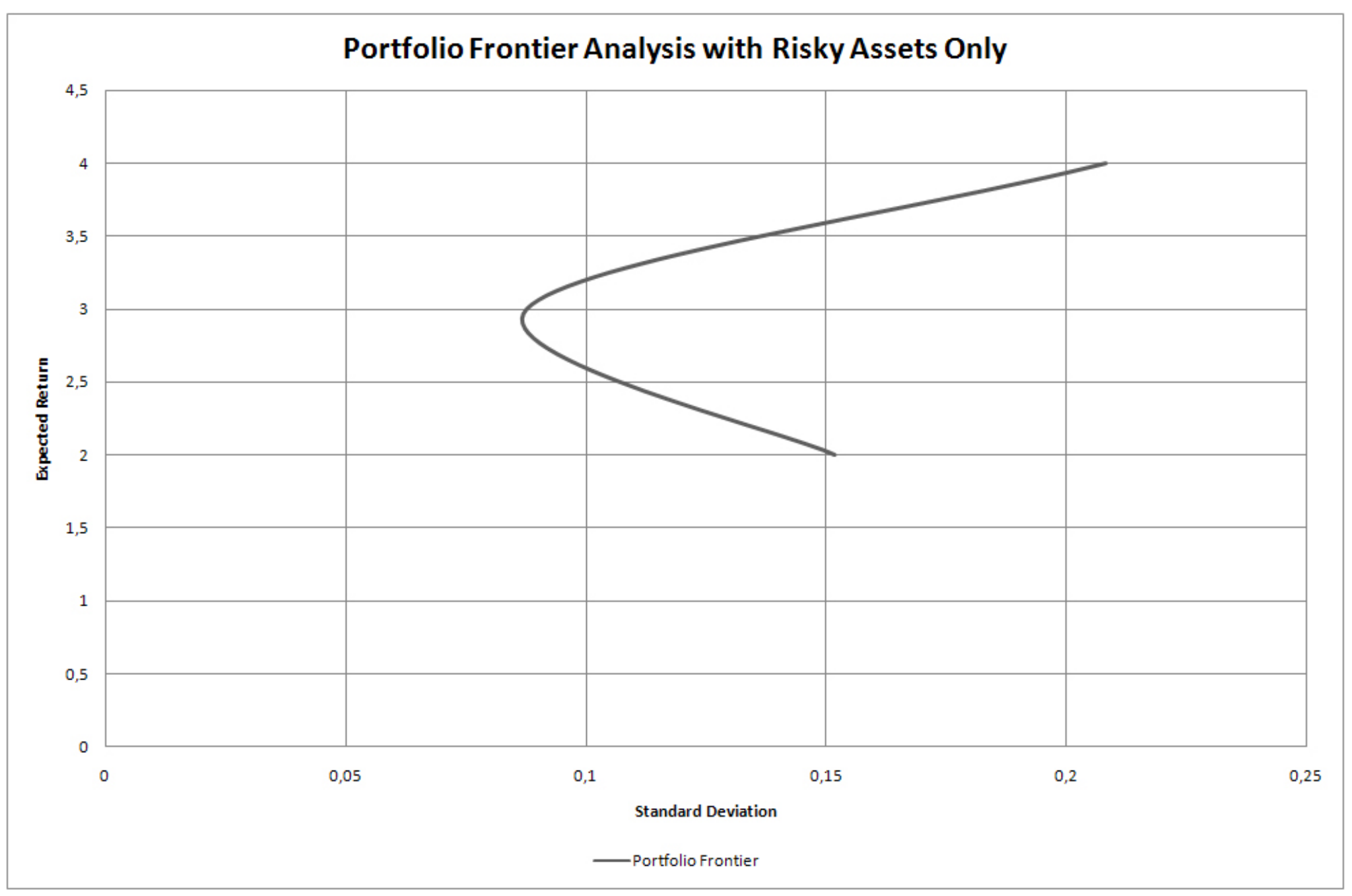

Figure 3: Portfolio Frontier Analysis with Risky Assets Only 


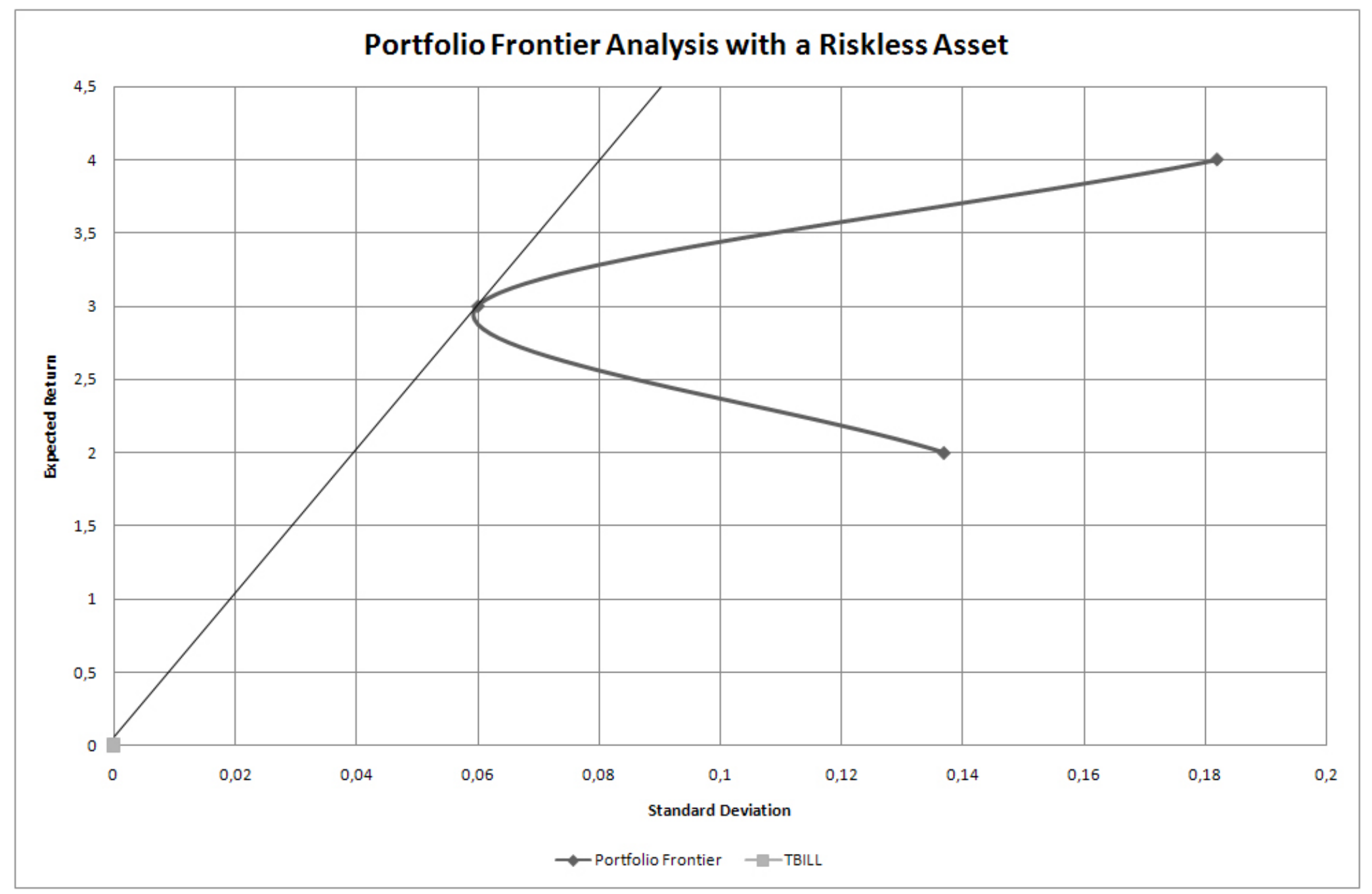

Figure 4: Portfolio Frontier Analysis with a Riskless Asset

Note: T-Bill refers to the U.S. Treasury Bills which are used as a proxy of a riskless asset. 


\begin{tabular}{|c|c|c|c|c|c|c|c|c|c|}
\hline & $\begin{array}{c}\text { RT ECX } \\
\text { DEC08 }\end{array}$ & RT GAS & RT ELEC & RT COAL & RT OIL & RT WEA & RT CER & RT BOND & RT EUR \\
\hline $\begin{array}{c}\text { Expected } \\
\text { Return }\end{array}$ & $-0,0018$ & 0,0338 & $-0,0211$ & 0,0027 & 0,0053 & 0,4321 & 0,01702381 & 2,83286E-05 & $-0,161643059$ \\
\hline Std Deviation & 0,614890277 & 2,824325206 & 10,78246731 & 0,999584701 & 1,41804319 & 5,196337234 & 0,399817029 & 0,039726132 & 8,767931502 \\
\hline
\end{tabular}

Table 1: Expected Return and Standard Deviation for Energy, Bond and Equity Assets

Note: RT stands for returns, Std Deviation for standard deviation, ECX DEC08 for the ECX carbon futures contract of maturity December 2008, Gas for the natural gas variable, Elec for the electricity variable, Coal for the coal variable, Oil for the crude oil variable, WEA for the weather derivatives contract, CER for the Certified Emissions Reduction valid under the Kyoto Protocol, Bond for the bond variable, and EUR for the Euronext 100 price index as defined above. 


\begin{tabular}{|c|c|c|c|c|c|c|c|c|c|}
\hline & RT DEC08 & RT GAS & RT ELEC & RT COAL & RT OIL & RT WEA & RT CER & RT BOND & RT EUR \\
\hline RT DEC08 & 1 & & & & & & & & \\
\hline RT GAS & $-0,083843348$ & 1 & & & & & & & \\
\hline RT ELEC & 0,03238164 & $-0,031102759$ & 1 & & & & & & \\
\hline RT COAL & $-0,027721224$ & $-0,006438851$ & $-0,062186799$ & 1 & & & & & \\
\hline RT OIL & $-0,001466019$ & $-0,026542535$ & 0,036280144 & 0,008111349 & 1 & & & & \\
\hline RT WEA & 0,047632133 & 0,002645503 & 0,031059249 & $-0,087117043$ & 0,021932909 & 1 & & & \\
\hline RT CER & $-0,050862875$ & 0,056893671 & $-0,022524169$ & $-0,018719988$ & $-0,087943419$ & $-0,08034643$ & 1 & & \\
\hline RT BOND & $-0,037261286$ & $-0,017078898$ & $-0,039683893$ & $-0,042892797$ & 0,003310712 & 0,05231719 & $-0,054683998$ & 1 & \\
\hline RT EUR & 0,048495721 & $-0,031195733$ & 0,017930111 & 0,026260248 & 0,044474849 & $-0,0001236$ & 0,018837533 & 0,328404693 & 1 \\
\hline
\end{tabular}

\section{Table 2: Correlation Matrix between Energy, Bond and Equity Assets}

Note: RT stands for returns, Std Deviation for standard deviation, ECX DEC08 for the ECX carbon futures contract of maturity December 2008, Gas for the natural gas variable, Elec for the electricity variable, Coal for the coal variable, Oil for the crude oil variable, WEA for the weather derivatives contract, CER for the Certified Emissions

Reduction valid under the Kyoto Protocol, Bond for the bond variable, and EUR for the Euronext 100 price index as defined above. 


\begin{tabular}{|c|c|c|c|c|c|c|c|c|c|c|}
\hline & RT_BOND & RT_CER & RT_COAL & RT_ECX & RT_ELEC & RT_EUR & RT_GAS & RT_OIL & $\overline{\text { RT_TBILL }}$ & RT_WEA \\
\hline Mean & 0.000963 & 0.017024 & 0.029840 & -0.001818 & -0.039664 & 0.085487 & 0.035882 & 0.014558 & -0.001253 & 0.432105 \\
\hline Median & 0.000000 & 0.000000 & 0.040000 & 0.020000 & -1.091000 & 0.510000 & -0.050000 & -0.038158 & 0.000000 & 0.000000 \\
\hline Maximum & 0.120000 & 1.530000 & 4.560000 & 3.650000 & 39.71300 & 28.39000 & 22.65000 & 11.77371 & 0.750000 & 17.00000 \\
\hline Minimum & -0.120000 & -1.310000 & -3.740000 & -7.400000 & -34.05300 & -32.65000 & -21.55000 & -12.84609 & -0.490000 & -15.59999 \\
\hline Std. Dev. & 0.035708 & 0.399817 & 0.867270 & 0.614890 & 10.52693 & 8.149984 & 2.782299 & 1.468422 & 0.063300 & 5.196337 \\
\hline Skewness & 0.071808 & 0.561290 & -0.117488 & -2.244994 & 0.667781 & -0.417292 & 0.668721 & -0.008155 & 0.956086 & 0.015606 \\
\hline Kurtosis & 3.355982 & 5.053116 & 6.386975 & 29.79303 & 5.177692 & 4.645799 & 18.30428 & 14.43857 & 35.80764 & 3.820959 \\
\hline
\end{tabular}

Table 3: Descriptive Statistics for Energy, Bond and Equity Asset Returns

Note: RT stands for returns, Std Deviation for standard deviation, ECX DEC08 for the ECX carbon futures contract of maturity December 2008, Gas for the natural gas variable, Elec for the electricity variable, Coal for the coal variable, Oil for the crude oil variable, WEA for the weather derivatives contract, CER for the Certified Emissions

Reduction valid under the Kyoto Protocol, Bond for the bond variable, and EUR for the Euronext 100 price index as defined above. 


\begin{tabular}{|c|c|c|}
\hline \multicolumn{3}{|c|}{ Dependent Variable: $E\left(\mathbf{R}_{E C X}\right)-R_{f}$} \\
\hline & Coefficient & Std. Error \\
\hline$\alpha_{1}$ & $0.233822^{\star \star \star}$ & 0.018746 \\
\hline$\alpha_{0}$ & $0.030971^{\star \star \star}$ & 0.015919 \\
\hline$\beta_{n}$ & -0.001871 & 0.002132 \\
\hline & \multicolumn{2}{|c|}{ Variance Equation } \\
\hline$\omega$ & $0.206975^{\star \star \star}$ & 0.008719 \\
\hline$\varphi$ & $0.517981^{\star \star \star}$ & 0.029673 \\
\hline
\end{tabular}

\begin{tabular}{lr}
\hline Diagnostic Tests & \\
\hline R-squared & 0.010182 \\
\hline Adjusted R-squared & 0.005920 \\
\hline $\boldsymbol{\varepsilon}_{\boldsymbol{n}}$ & 0.614371 \\
\hline Log likelihood & 772.3144 \\
\hline Durbin-Watson stat & 2.173891 \\
\hline AlC & 1.664485 \\
\hline SC & 1.690392 \\
\hline F-statistic & 0.049384 \\
\hline ARCH Test & 0.463494 \\
\hline$Q(20)$ & 32.826 \\
\hline
\end{tabular}

\section{Table 4: CAPM Regression Results for the ECX DEC08 carbon futures contract with a ARCH(1,1) model}

Note: Bollerslev-Wooldridge robust standard errors. $A I C$ refers to the Akaike Information Criterion, $S C$ refers to the Schwarz Criterion, $Q(20)$ refers to the Ljung-Box $Q$ Statistic with a maximum number of lags of 20 . The value for the F-Statistic is the p-value. 


\begin{tabular}{|c|c|c|}
\hline \multicolumn{3}{|c|}{ Dependent Variable: $E\left(R_{G A S}\right)-R_{f}$} \\
\hline & Coefficient & Std. Error \\
\hline$\alpha_{1}$ & $-0.148277^{\star \star \star}$ & 0.019587 \\
\hline$\alpha_{0}$ & -0.049021 & 0.036290 \\
\hline$\beta_{n}$ & $-0.015294^{\star \star \star}$ & 0.0001 \\
\hline & \multicolumn{2}{|c|}{ Variance Equation } \\
\hline$\omega$ & $3.641193^{\star \star \star}$ & 0.083878 \\
\hline$\varphi$ & $0.976279^{\star \star \star *}$ & 0.058441 \\
\hline
\end{tabular}

\begin{tabular}{lr}
\hline Diagnostic Tests & \\
\hline$R$-squared & 0.011125 \\
\hline Adjusted R-squared & 0.006867 \\
\hline $\boldsymbol{\varepsilon}_{n}$ & 2.775468 \\
\hline Log likelihood & 2159.681 \\
\hline Durbin-Watson stat & 1.927542 \\
\hline AIC & 4.635291 \\
\hline$S C$ & 4.661198 \\
\hline F-statistic & 0.034141 \\
\hline ARCH Test & 0.437272 \\
\hline$Q(20)$ & 31.948 \\
\hline
\end{tabular}

Table 5: CAPM Regression Results for the Natural Gas Variable with a ARCH(1,1) model

Note: Bollerslev-Wooldridge robust standard errors. $A I C$ refers to the Akaike Information Criterion, $S C$ refers to the Schwarz Criterion, $Q(20)$ refers to the Ljung-Box $Q$ Statistic with a maximum number of lags of 20 . The value for the F-Statistic is the p-value. 


\begin{tabular}{|c|c|c|}
\hline \multicolumn{3}{|c|}{ Dependent Variable: $E\left(R_{E L E C}\right)-R_{f}$} \\
\hline & Coefficient & Std. Error \\
\hline$\alpha_{1}$ & $-0.193808^{\star \star \star}$ & 0.027463 \\
\hline$\alpha_{0}$ & -0.024556 & 0.252310 \\
\hline$\beta_{n}$ & -0.005041 & 0.033414 \\
\hline & \multicolumn{2}{|c|}{ Variance Equation } \\
\hline $\boldsymbol{\omega}$ & $52.71211^{\star \star \star}$ & 2.026832 \\
\hline$\varphi$ & $0.385487^{\star \star \star}$ & 0.051454 \\
\hline
\end{tabular}

\begin{tabular}{lr}
\hline Diagnostic Tests & \\
\hline$R$-squared & 0.288642 \\
\hline Adjusted R-squared & 0.282395 \\
\hline $\boldsymbol{\varepsilon}_{\boldsymbol{n}}$ & 8.973819 \\
\hline Log likelihood & 3270.581 \\
\hline Durbin-Watson stat & 1.876152 \\
\hline AlC & 7.129523 \\
\hline SC & 7.176718 \\
\hline F-statistic & 0.000000 \\
\hline ARCH Test & 0.386772 \\
\hline$Q(20)$ & 43.851 \\
\hline
\end{tabular}

\section{Table 6: CAPM Regression Results for the Electricity Variable with a $\operatorname{ARCH}(1,1)$ model}

Note: Bollerslev-Wooldridge robust standard errors. $A I C$ refers to the Akaike Information Criterion, $S C$ refers to the Schwarz Criterion, $Q(20)$ refers to the Ljung-Box $Q$ Statistic with a maximum number of lags of 20 . The value for the $F$-Statistic is the p-value. 


\begin{tabular}{|c|c|c|}
\hline \multicolumn{3}{|c|}{ Dependent Variable: $E\left(R_{\text {COAL }}\right)-R_{f}$} \\
\hline & Coefficient & Std. Error \\
\hline$\alpha_{1}$ & -0.017292 & 0.025569 \\
\hline$\alpha_{0}$ & $0.069475^{\star \star \star}$ & 0.018898 \\
\hline$\beta_{n}$ & $-0.003782^{*}$ & 0.002333 \\
\hline & \multicolumn{2}{|c|}{ Variance Equation } \\
\hline $\boldsymbol{\omega}$ & $0.420828^{\star \star \star}$ & 0.016661 \\
\hline$\varphi$ & $0.541561^{\star \star *}$ & 0.059253 \\
\hline
\end{tabular}

\begin{tabular}{lr}
\hline Diagnostic Tests & \\
\hline$R$-squared & 0.032222 \\
\hline Adjusted R-squared & 0.007541 \\
\hline $\boldsymbol{\varepsilon}_{\boldsymbol{n}}$ & 0.875754 \\
\hline Log likelihood & 1125.123 \\
\hline Durbin-Watson stat & 2.040838 \\
\hline AlC & 2.419964 \\
\hline SC & 2.445871 \\
\hline F-statistic & 0.000000 \\
\hline ARCH Test & 0.149836 \\
\hline$Q(20)$ & 32.806 \\
\hline
\end{tabular}

\section{Table 7: CAPM Regression Results for the Coal Variable with a ARCH(1,1) model}

Note: Bollerslev-Wooldridge robust standard errors. $A I C$ refers to the Akaike Information Criterion, $S C$ refers to the Schwarz Criterion, $Q(20)$ refers to the Ljung-Box $Q$ Statistic with a maximum number of lags of 20 . The value for the $F$-Statistic is the p-value. 


\begin{tabular}{ccc}
\hline Dependent Variable: $\mathbf{E}\left(\mathbf{R}_{\mathrm{OIL}}\right)-\boldsymbol{R}_{\mathbf{f}}$ \\
\hline & Coefficient & Std. Error \\
\hline $\boldsymbol{\alpha}_{1}$ & $-0.053927^{\star \star}$ & 0.026455 \\
\hline $\boldsymbol{\alpha}_{0}$ & -0.048182 & 0.038928 \\
\hline $\boldsymbol{\beta}_{\mathrm{n}}$ & 0.004600 & 0.005541 \\
\hline $\boldsymbol{3}$ Variance Equation \\
\hline $\boldsymbol{\omega}$ & $1.304628^{\star \star \star}$ & 0.074932 \\
\hline $\boldsymbol{\varphi}$ & $0.392536^{\star \star \star}$ & 0.052151 \\
\hline
\end{tabular}

\begin{tabular}{lr}
\hline Diagnostic Tests & \\
\hline$R$-squared & 0.010448 \\
\hline Adjusted R-squared & 0.006188 \\
\hline $\boldsymbol{\varepsilon}_{n}$ & 1.467020 \\
\hline Log likelihood & 1604.130 \\
\hline Durbin-Watson stat & 2.157620 \\
\hline AlC & 3.445675 \\
\hline SC & 3.471582 \\
\hline F-statistic & 0.044520 \\
\hline ARCH Test & 0.998397 \\
\hline Q(20) & 26.224 \\
\hline
\end{tabular}

Table 8: CAPM Regression Results for the Oil Variable with a ARCH(1,1) model

Note: Bollerslev-Wooldridge robust standard errors. $A I C$ refers to the Akaike Information Criterion, $S C$ refers to the Schwarz Criterion, $Q(20)$ refers to the Ljung-Box $Q$ Statistic with a maximum number of lags of 20 . The value for the F-Statistic is the p-value. 


\begin{tabular}{ccc}
\hline Dependent Variable: $\mathbf{E}\left(\boldsymbol{R}_{\text {WEA }}\right)-\boldsymbol{R}_{\mathbf{f}}$ \\
\hline & Coefficient & Std. Error \\
\hline $\boldsymbol{\alpha}_{1}$ & $0.131258^{\star \star}$ & 0.060792 \\
\hline $\boldsymbol{\alpha}_{\mathbf{0}}$ & 0.352982 & 0.258217 \\
\hline $\boldsymbol{\beta}_{\mathbf{n}}$ & -0.030425 & 0.027680 \\
\hline $\boldsymbol{c}$ Variance Equation \\
\hline $\boldsymbol{\omega}$ & $22.38411^{\star \star \star}$ & 1.890043 \\
\hline $\boldsymbol{\varphi}$ & $0.165212^{\star \star}$ & 0.077231 \\
\hline
\end{tabular}

\begin{tabular}{lr}
\hline Diagnostic Tests & \\
\hline$R$-squared & 0.008427 \\
\hline Adjusted R-squared & 0.002178 \\
\hline $\boldsymbol{\varepsilon}_{\boldsymbol{n}}$ & 5.205682 \\
\hline Log likelihood & 1155.894 \\
\hline Durbin-Watson stat & 2.039692 \\
\hline AlC & 6.126092 \\
\hline$S C$ & 6.178038 \\
\hline F-statistic & 0.052922 \\
\hline ARCH Test & 0.861886 \\
\hline Q(20) & 11.509 \\
\hline
\end{tabular}

Table 9: CAPM Regression Results for the Weather Variable with a ARCH(1,1) model

Note: Bollerslev-Wooldridge robust standard errors. $A I C$ refers to the Akaike Information Criterion, $S C$ refers to the Schwarz Criterion, $Q(20)$ refers to the Ljung-Box $Q$ Statistic with a maximum number of lags of 20 . The value for the F-Statistic is the p-value. 


\begin{tabular}{crr}
\hline \multicolumn{3}{c}{ Dependent Variable: $\mathbf{E}\left(\mathbf{R}_{\text {BOND }}\right)-\boldsymbol{R}_{\mathbf{f}}$} \\
\hline & Coefficient & Std. Error \\
\hline $\boldsymbol{\alpha}_{1}$ & $0.213099^{\star \star \star}$ & 0.011935 \\
\hline $\boldsymbol{\alpha}_{0}$ & 0.000901 & 0.001663 \\
\hline $\boldsymbol{\beta}_{\mathrm{n}}$ & $0.001360^{\star \star \star}$ & 0.000140 \\
\hline $\boldsymbol{3}$ Variance Equation \\
\hline $\boldsymbol{\omega}$ & $0.002116^{\star \star \star}$ & 0.000123 \\
\hline $\boldsymbol{\varphi}$ & $0.785840^{\star \star \star}$ & 0.048804 \\
\hline
\end{tabular}

\begin{tabular}{lr}
\hline Diagnostic Tests & \\
\hline$R$-squared & 0.017500 \\
\hline Adjusted R-squared & 0.013270 \\
\hline $\boldsymbol{\varepsilon}_{n}$ & 0.070768 \\
\hline Log likelihood & 1282.670 \\
\hline Durbin-Watson stat & 2.167503 \\
\hline AlC & 2.735911 \\
\hline SC & 2.710004 \\
\hline F-statistic & 0.002505 \\
\hline ARCH Test & 0.110491 \\
\hline$Q(20)$ & 32.9337 \\
\hline
\end{tabular}

Table 10: CAPM Regression Results for the Bond Variable with a ARCH(1,1) model

Note: Bollerslev-Wooldridge robust standard errors. $A I C$ refers to the Akaike Information Criterion, $S C$ refers to the Schwarz Criterion, $Q(20)$ refers to the Ljung-Box $Q$ Statistic with a maximum number of lags of 20 . The value for the F-Statistic is the p-value. 


\begin{tabular}{|c|c|c|}
\hline \multicolumn{3}{|c|}{ Dependent Variable: $E\left(R_{C E R}\right)-R_{f}$} \\
\hline & Coefficient & Std. Error \\
\hline$\alpha_{1}$ & $0.124443^{\star \star \star}$ & 0.050585 \\
\hline$\alpha_{0}$ & 0.004425 & 0.026743 \\
\hline$\beta_{n}$ & 0.001311 & 0.002119 \\
\hline \multicolumn{3}{|c|}{ Variance Equation } \\
\hline$\omega$ & $0.104057^{* \star *}$ & 0.009300 \\
\hline$\varphi$ & $0.445578^{\star \star \star}$ & 0.118872 \\
\hline
\end{tabular}

\begin{tabular}{lr}
\hline Diagnostic Tests & \\
\hline$R$-squared & 0.007763 \\
\hline Adjusted R-squared & 0.008371 \\
\hline $\boldsymbol{\varepsilon}_{\boldsymbol{n}}$ & 0.410895 \\
\hline Log likelihood & 118.7581 \\
\hline Durbin-Watson stat & 2.044370 \\
\hline AlC & 0.986121 \\
\hline SC & 1.056349 \\
\hline F-statistic & 0.074957 \\
\hline ARCH Test & 0.324762 \\
\hline$Q(20)$ & 19.467 \\
\hline
\end{tabular}

Table 11: CAPM Regression Results for the CER contract with a ARCH(1,1) model

Note: Bollerslev-Wooldridge robust standard errors. $A I C$ refers to the Akaike Information Criterion, $S C$ refers to the Schwarz Criterion, $Q(20)$ refers to the Ljung-Box $Q$ Statistic with a maximum number of lags of 20 . The value for the F-Statistic is the p-value. 